\title{
Nocardiose pulmonar em paciente usuário crônico de corticóides
}

\author{
Pulmonary nocardiosis in a patient who was \\ a chronic corticosteroid user
}

\author{
Renata Maria Ferreira Brasileiro ${ }^{1}$, André Carvalho Caribe de Araújo Pinho ${ }^{1}$, \\ Catarine Silva Medeiros ${ }^{1}$, Francisco Ferri' ${ }^{2}$, Leonardo de Lucca Schiavon ${ }^{1}$, \\ Janaína Luz Narciso-Schiavon ${ }^{1}$ e Fernando Costa Buzzoleti ${ }^{1}$
}

\begin{abstract}
RESUMO
Nocardiose pulmonar é uma infecção grave e incomum causada pela Nocardia ssp, microorganismos que podem se comportar tanto como oportunistas quanto patógenos primários e que pode se apresentar como desordem aguda ou crônica supurativa. Relata-se o caso de um paciente de 49 anos, portador de púrpura trombocitopênica idiopática em tratamento com corticóides que desenvolveu infecção pulmonar por Nocardia farcinica, isolada em hemocultura. Apesar de tratamento correto com sulfametoxazol-trimetoprim, o paciente morreu após três meses de instituída terapia.
\end{abstract}

Palavras-chaves: Nocardiose. Púrpura trombocitopênica. Hospedeiro imunocomprometido. Pneumopatias.

\section{ABSTRACT}

Pulmonary nocardiosis is an infrequent and severe infection caused by Nocardia spp. These are microorganisms that may behave both as opportunists and as primary pathogens, and they may present as either acute or suppurative chronic disorders. We report on the case of a 49-year-old man with idiopathic thrombocytopenic purpura that was being treated with corticosteroids. He developed pulmonary infection due to Nocardia farcinica, which was isolated from blood cultures. Despite correct treatment with trimethoprim-sulfamethoxazole, the patient died three months after this therapy was instituted.

Key-words: Nocardiosis. Thrombocytopenic purpura. Immunocompromised host. Lung diseases.

A nocardiose é uma infecção bacteriana subaguda ou crônica que provoca uma resposta supurativa e acomete principalmente pulmão e pele, mas pode se disseminar via hematogênica para 0 sistema nervoso central e outros tecidos ${ }^{20}$. As nocardias são actinomicetos aeróbicos gram positivos que vivem no solo como saprófitas e ocasionalmente infectam o homem através de inalação de aerossóis ${ }^{6}$. A taxa de mortalidade global para pacientes com nocardiose varia de 44 a $85 \%$, a depender do perfil imunológico do hospedeiro ${ }^{12}$.

\section{RELATO DE CASO}

Paciente do sexo masculino, 49 anos, apresentou-se com queixa de mal estar geral, perda de apetite, tosse seca, dor para deglutir e febre alta a três semanas da admissão. Era acompanhado no serviço de clinica médica do Hospital Heliópolis com diagnóstico de púrpura trombocitopênica idiopática há quatro anos e esplenectomizado há quatro meses. Quando procurou este serviço, estava em uso de prednisona 1mg/kg/dia. Ex-tabagista, 45 anos/maço.

Ao exame físico apresentava-se em bom estado geral, levemente hipocorado, fascies cushingóide, temperatura axilar de $38^{\circ} \mathrm{C}$, freqüência cardíaca de $90 \mathrm{bpm}$, pressão arterial de 130/80mmHg e freqüência respiratória de 20rpm. Cavidade oral com placas esbranquiçadas removíveis, lesão herpetiforme em língua. À palpação cervical, apresentava nódulo tireoidiano sólido e indolor de aproximadamente dois centímetros. Aparelho respiratório com estertores crepitantes difusos bilaterais e ausculta cardíaca sem alterações.

Seus exames laboratoriais evidenciaram hemoglobina de $10,9 \mathrm{~g} / \mathrm{dl}$, leucócitos de $23.100 \mathrm{~mm}^{3}$ com $7 \%$ bastões e

\footnotetext{
1. Serviço de Clínica Médica, Hospital Heliópolis, São Paulo, SP. 2. Serviço de Radiologia, Hospital Heliópolis, São Paulo, SP. Address to: Dr. Fernando Costa Buzzoleti. R. Cônego Xavier 276/4 andar, Vila Heliópolis, 04231-902 São Paulo, SP.

Telefax: $55112274-7600$ ramal 103

e-mail: fernandocbuzzoleti@terra.com.br

Recebido para publicação em: 04/09/2006

Aceito em: 20/08/2007
} 
$86 \%$ segmentados e 85.000 plaquetas. A dosagem de TSH foi de $0,02 \mathrm{UM} / \mathrm{ml}$ e o T4 livre 5,08ng/dl. A gasometria arterial mostrou $\mathrm{pH}=7,46 ; \mathrm{pCO}_{2}=33,2 ; \mathrm{pO}_{2}=61$ e $\mathrm{SO}_{2}=92,7 \%$. 0 exame do escarro com pesquisa para BAAR, fungos e sorologias para hepatites e HIV foram negativos.

Realizou-se ultra-sonografia de tireóide que mostrou formações nodulares heterogêneas, e a punção aspirativa com agulha fina, demonstrou achados citológicos compatíveis com tireoidite.

A radiografia de tórax (Figura 1) mostrava lesões nodulares bilaterais. A tomografia computadorizada de tórax (Figura 2) evidenciava opacidades mal definidas, com áreas de cavitação central localizadas em segmento superior do lobo inferior direito e segmento basal do lobo inferior esquerdo. Múltiplos nódulos esparsos pelo parênquima pulmonar predominando à direita, alguns com pequenas áreas de cavitações centrais.

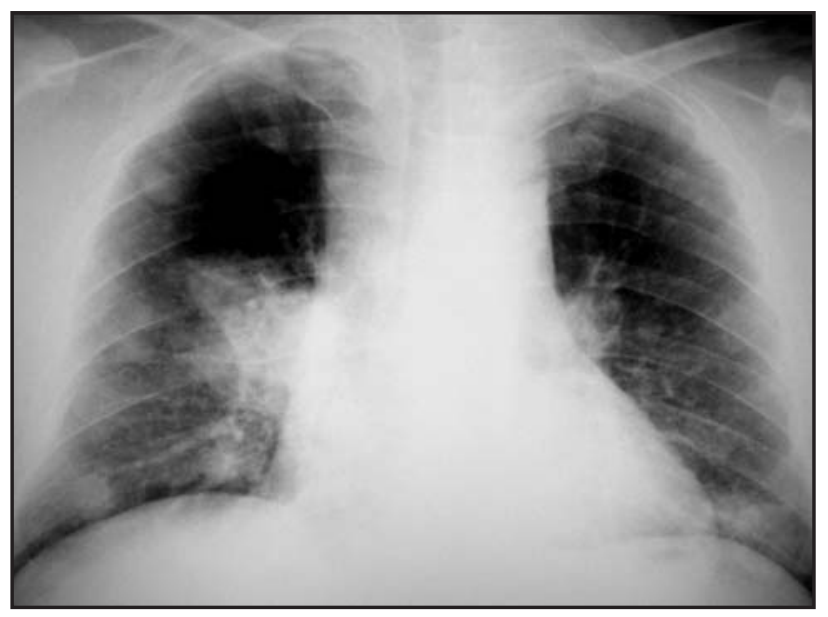

Figura 1 - Radiografia de tórax-nocardiose pulmonar.

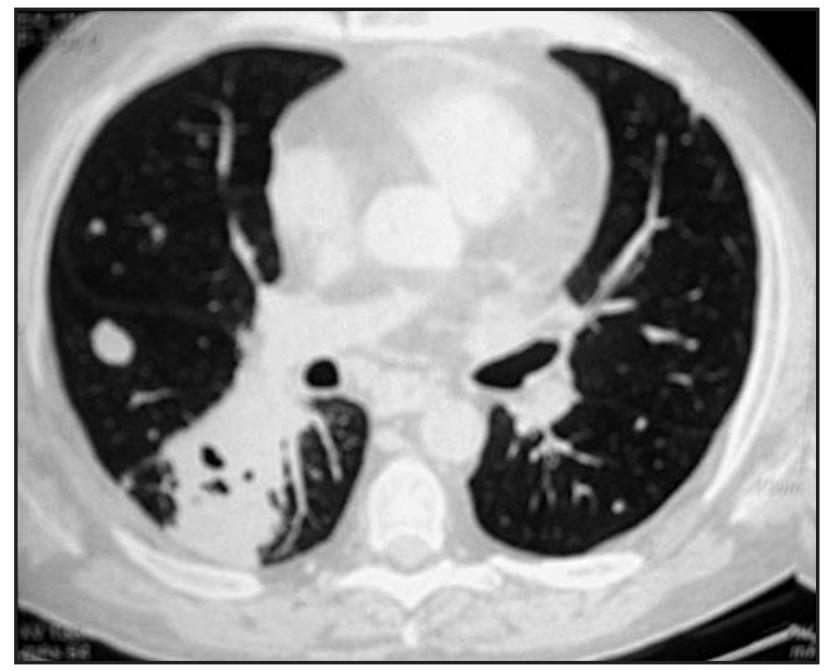

Figura 2 - Tomografia de tórax-nocardiose pulmonar.

Realizado broncofibroscopia com lavado broncoalveolar e biópsia, que mostrou apenas hemorragia intra-alveolar recente e antiga, e não elucidou o diagnóstico. Devido à piora clínica e febre alta diária, o paciente foi tratado empiricamente por 10 dias com cefepime, fluconazol e vancomicina, sem melhora.
Antes do início da antibioticoterapia empírica, foram colhidos dois pares de hemocultura (um para aeróbios e outro para anaeróbios), em sítios diferentes, com intervalo de 30 min. Cerca de duas semanas depois, a hemocultura revelou a presença bacilos Gram positivos não esporulados, compatíveis com Nocardia farcinica. A partir de então, o paciente foi tratado com sulfametoxazol-trimetroprim. Evoluiu com melhora clínica progressiva e recebeu alta hospitalar com programação de continuar o tratamento por, no mínimo, doze meses. Apresentou regressão dos sintomas gerais e do quadro respiratório nos primeiros três meses de seguimento ambulatorial, quando foi subitamente internado por recrudescimento da sintomatologia com rápida queda do estado geral e insuficiência respiratória, evoluindo para o óbito.

\section{DISCUSSÃO}

A nocardiose pulmonar é uma infecção rara e de evolução grave, que acomete principalmente pacientes debilitados e imunodeprimidos ${ }^{71119}$. Foram relatados casos de pacientes em tratamento com corticóide ou quimioterapia imunossupressora ${ }^{12910141618}$.Comumente se apresenta como doença subaguda ou crônica, podendo mimetizar tuberculose, abscesso ou câncer de pulmão ${ }^{16}$. Em humanos o complexo Nocardia asteróides é o patógeno predominante ${ }^{515}$. Este inclui: Nocardia asteróides sensu stricto, Nocardia farcinica, Nocardia nova. Porém, há relato de infecção humana por outras espécies como Nocardia brasilienses, Nocardia otitidiscaviarum, Nocardia paucivorans e Nocardia transvalensis ${ }^{3818}$. A doença causada pela Nocardia farcinica é menos comum, porém mais virulenta e mais implicada em infecções disseminadas ${ }^{17}$.

Já foram descritos casos de tireoidite por Nocardia $^{4}{ }^{13} \mathrm{e}$, apesar deste paciente ter apresentado tireoidite na vigência da infecção pulmonar, não pudemos comprovar associação etiológica entre o quadro tireoidiano e o pulmonar.

As manifestações clínicas da forma pulmonar são, geralmente, mal-estar geral, perda de peso, febre, suores noturnos e tosse produtiva $^{1} 914151819$. Os exames de imagem nos mostram uma grande variedade de formas de apresentação da doença, tais como: infiltrados leves ou difusos, consolidações lobares ou multilobares, nódulos ou massas (geralmente com cavitação) ${ }^{310}$. Outras manifestações radiológicas possíveis incluem opacidade em vidro fosco e pneumotórax ${ }^{10}$. Nódulos pulmonares com múltiplas cavitações podem ser facilmente confundidos com outras infecções pulmonares, como actinomicose e tuberculose, além de outras infecções fúngicas, êmbolos sépticos, sarcoidose, granulomatose de Wegener, neoplasias (como linfoma) e metástases $^{10}$.

O diagnóstico da infecção usualmente é feito por exame do escarro ou de secreções. Broncoscopia ou aspirado pulmonar são usualmente necessários nas infecções pulmonares. Hemoculturas também devem ser colhidas embora sua positividade seja incomum. Como são microorganismos de crescimento muito lento, várias semanas são necessárias para sua identificação nas culturas, como hemocultura e Agar chocolate ${ }^{151819}$. 
0 tratamento de escolha para nocardiose é sulfametoxazol $(50-100 \mathrm{mg} / \mathrm{kg})$ em combinação com trimetoprim $(10-20 \mathrm{mg} / \mathrm{kg})$ com duração de pelo menos doze meses em pacientes imunodeprimidos. Recidiva foi descrita em pacientes tratados por menos de seis meses. Em casos de impossibilidade do uso desta medicação, as melhores alternativas são a minociclina (200-400mg; via oral) e a amicacina $(10-15 \mathrm{mg} / \mathrm{kg}$; endovenosa) ${ }^{9151819}$.

Em conclusão, a nocardiose deve ser considerada no diagnóstico diferencial de pneumopatias em pacientes imunocomprometidos, e seu alto grau de suspeição éfundamental para o diagnóstico precoce e sucesso terapêutico.

\section{REFERÊNCIAS}

1. Baldi BG, Santana ANC, Takagaki TY. Nocardiose pulmonar e cutânea em paciente usuário de corticosteróide. Jornal Brasileiro de Pneumologia 32: 592-595, 2006.

2. Barata CH, Oliveira DAG, Colombo AL, Pereira CAP. Abscesso cerebral por Nocardia sp em paciente imunossuprimido. Revista da Sociedade Brasileira de Medicina Tropical 33: 609-612, 2000.

3. Beaman BL, Beaman L. Nocardia Species: Host-Parasite Relationships. Beaman and Beaman. Clinical Microbiology Reviews 7: 213-264, 1994.

4. Carriere C, Marchandin H, Andrieu JM, Vandome A, Perez C. Nocardia thyroiditis: unusual location of infection. Journal of Clinical Microbiology 37: 2323-2325, 1999.

5. Eshragh S, Amin M. Nocardia asteroids Complex in Patient with Symptomatic Pulmonary Nocardiosis. Iranian Journal of Public Health 30: 99-102, 2001.

6. Ferrer A, Llorença V, Codina G, Gracia-Roldán J. [Nocardiosis and bronchiectasis. An uncommon association?]. Enfermedades Infecciosas e Microbiología Clínica 23: 62-66; 2005.

7. Filice GA. Nocardiosis in persons with human immunodeficiency virus infection, transplant recipients, and large, geographically defined populations. The Journal of Laboratory and Clinical Medicine 145: 156-162, 2005.
8. Gray TJ, Serisier DJ, Gilpin CM, Coulter C, Bowler SJ, McComck JG. Nocardia paucivorans - A cause of disseminated Nocardiosis. Journal of Infection 54: 95-98, 2007.

9. Hizel K, Caglar K, Cabadak H, Kulah C. Pulmonary nocardiosis in a non-Hodgkin's lymphoma patient.Infection 30: 243-245, 2002.

10. Hwang JH, Koh WJ, Suh GY, Chung MP, Kim H, Kwon OJ, Lee KS, Lee NY, Han J. Pulmonary nocardiosis with multiple cavitary nodules in a HIV-negative immunocompromised patient. Internal Medicine 43: 852-854, 2004.

11. Jajiæ-Benèiæ IJ, Gaæina $P$, Kataliniæ-Jankoviæ V, Benèiæ I. Nocardia asteroids pulmonary infection: a case report. Acta Clinica Croatica 41: 259-262; 2002.

12. Lederman ER, Nancy FC. A case series and focused review of Nocardiosis. Clinical and microbiologic Aspects. Medicine (Baltimore) 83: 300-313; 2004.

13. Lewen SR, Street AC, Snider J. Suppurative thyroiditis due to Nocardia asteroides. Journal of Infection 26:339-340, 1993.

14. Maeno Y, Sando Y, Ubukata M, Maeno T, Tajima S, Hosono T, Sato M, Tsukagoshi M, Suga T, Kurabayashi M, Nagai R. Pulmonary nocardiosis during immunosuppressive therapy for idiopathic pulmonary fibrosis. Respirology 5: 393-395, 2000.

15. Menendez R, Cordero PJ, Santos M, Gobernado M, Marco V. Pulmonary infection with Nocardia species: a report of 10 cases and review. The European Respiratory Journal 10: 1542-1546, 1997.

16. Narushima M, Suzuki H, Kasai T, Tsuzura Y, Tomita S, Endoh S, Yamada M, Ohtsuka H. Pulmonary nocardiosis in a patient treated with corticosteroid therapy. Respirology 7: 87-89, 2002.

17. Quinn MP, Courtney AE, McCarron MO, McCluskey M, Hedderwick S. Breathless and dizzy! disseminated Nocardia farcinica complicating renal transplantation. Nephrology Dialysis and Transplantion, 2007.

18. Safdar N, Kaul DR, Saint S. Clinical problem-solving. Into the Woods. The New England Journal of Medicine 356: 943-947, 2007.

19. Tomas RM, Villanueva RM, Calzada SR, Durantez MS, Tarazona JMV, Alapont MM, Serrano MG. Pulmonary nocardiosis: Risk factors and outcomes. Respirology 12: 394-400, 2007.

20. Wadhwa V, Rai S, Kharbanda P, Kabra S, Gur R, Sharma VK. A fatal pulmonary infection by Nocardia brasiliensis. Indian Journal Medicine Microbiology 24: 63-64, 2006. 